\title{
Design and fabrication of low-cost micromachining system for prototyping printed circuit boards
}

DOI:10.36909/jer.ICMMM.12425

\author{
Dhinesh S K*, Senthil Kumar K L, Megalingam A, Gokulraj A P
}

Department of Mechatronics, Bannari Amman Institute of Technology, Sathyamangalam, Erode-638401, Tamil Nadu, India.

*Email: dhineshmemts@gmail.com; Corresponding Author.

\begin{abstract}
Printed circuit boards (PCBs) have a portentous position in constructing modern electronic equipment. Currently, chemical etching is the process used to produce PCBs at huge volumes, which is not suitable for preparing prototypes. The working environment is also not an encouraging one. There is no economical way to manufacture PCBs in low volumes, which is the basic requirement for Small and Medium Scale Enterprises (SMEs). Prototyping the desired circuit boards, prior to the mass production, is essential to avoid major losses by producing faulty designs. Developing a low-cost machine for prototyping PCBs may overcome these drawbacks. Hence, in this work, a machine capable of performing PCB mechanical milling operation on wide range of materials like copper/epoxy boards and flexible substrates has been developed. The machine developed is capable of milling lines that are $0.3 \mathrm{~mm}$ in width and $0.46 \mathrm{~mm}$ in depth. The performance of the machine reveals that it can mill any complex shapes and designs with expected accuracy. Selection of hardware components according to the needs would reduce the cost and programming snag further, which makes it affordable to SMEs.
\end{abstract}

Key words: CNC milling; EAGLE CAD; ESTLCAM; micro stepping; PCB. 


\section{INTRODUCTION}

In the year 1900, Charles Ducas bagged the patent for printed wiring and then evolved the Printed Circuit Boards (PCBs). PCBs consist of a number of active and passive electronic components such as transistors, triodes, resistors, etc. that makes it practically possible to build large circuits. PCBs has an impact on electronic equipment production as it eliminates the previous bulky designs and reduces the cost and time. Different applications require their own printed circuit boards and indirect properties favoring the surroundings of that particular equipment.

PCBs act as mechanical support and makes connections to the outside world to get power, exchange information, or display results connect. Copper is deposited on a non-conductive substrate layer in a range of 0.7 mils to 2.8 mils based on the application needs. These copper layers are stripped off by various methods, including conventional and non-conventional methods. Earlier PCBs were one sided only and the back side was utilized to assemble the components by soldering or riveting later double-sided boards came into existence and then surface mounted components were placed on both the side board using solder paste. Printed circuit milling, also known as isolation milling, is the process of removing unwanted materials of copper from the sheet of PCB material (Copper Clad board) to recreate the pads and structures as per the required pattern. There is no template to construct a standard PCB miller as it is completely based on the customer requirement. Small industries cannot have a facility by their own because of which they have to depend on outsourcing agencies. Chances of design theft is also an important factor, which could not be neglected. Moreover, the present technology is practiced with chemical hazardous environment that causes discomfort to the working personnel. Therefore, the objective of this work is to develop a portable, low cost, PCB milling machine that meets out the industrial expectations well 


\section{LITERATURE SURVEY}

Currently, a lot of research is happening around in building a low-cost PCB prototyping with higher accuracy and repeatability. Hodges et al. (1995) employed machine vision system for PCB drilling operation-using robot. The position of end effector was aligned with work piece and the process was carried out in which the vision system calibration was not required. This method was effective with low volume PCB drilling. Shan et al. (1998) developed an automatic PCB drilling machine with a computer vision system for auto aligning of PCB and capable of carrying out inspection. The system reported a good operating efficiency with higher repeatability factor of more than $5 \mu \mathrm{m}$. The PCB drilling is a tedious process, which depends on various factors such as drilling force, PCB structure, temperature, process, etc. (Zheng et al., 2011).

Ferdinando et al., (2006) developed an automatic open loop PCB drilling machine, which accepts the inputs via PCB drawing software. It used two axes with an error value of $2.34 \%$ and $4.34 \%$ respectively. The developed machine achieved a time cycle of 90 holes with 100 mils depth in an average time of 5 minutes, which was efficient when compared to many traditional machines. It was observed that further efficiency could be improved by applying changes in the motor step angle. Jack Ou et al. (2014) developed a new method of creating a PCB pattern using photopolymer film exposed to ultraviolet (UV) rays. The transparent photosensitive film was placed over the PCB and then subjected to UV rays and etched using sodium carbonate solution was an analogous to photolithography process. In this, the resolution of the low-cost PCB fabrication process was analyzed.

Alim et al. (2016) fabricated a PIC microcontroller based 3-axis automatic PCB drilling machine, which was using both stepper motor ( $\mathrm{X}$ and $\mathrm{Y}$-axis) and servo motor (Z-axis) to perform the drilling operation. The performance of the machine was tested with different dimensions and different hole location. The maximum PCB size of $88 \mathrm{~mm}$ can be drilled. 
Planning et al. (2014) have developed an automatic PCB drilling machine with Travelling Salesman Problem (TSP) algorithm. This model used a camera system for image processing that detects the hole locations and mapped the shortest path between the holes. In this process, the maximum travel time is reduced using the shortest path algorithm. In another study, Tahir et al. (2010) have used Euclidean TSP method of optimization for fabricating CNC PCB Drilling Machine with novel friendly approach. ATmega8535 microcontroller was used because of its advanced RISC architecture availability. This novel approach has resulted in the reduction of travelling time up to $10 \%$.

Basniak et al. (2012) designed a PCB milling machine with the functional modelling and reported that even using simple metric threaded bars, without precision machinery, high levels of repeatability was possible. The major problem was with aligning the tool concentric to the spindle axis. An automatic drilling machine using 8051 microcontrollers with a maximum PCB size of $12 \mathrm{~cm}$ (L) X $20 \mathrm{~cm}$ (W) was fabricated in which the stepper motor was used to move the shaft in all three directions (Balasubramanyam et al., 2014). The input was fed through the personal computer (PC) with MAX 232, which acted as an interface between PC and microcontroller. This machine exhibited better performance than the previous systems. Hyacinth et al. (2015) had reviewed the precision improvement in micro- drilling process that explored the accuracy in micro drilling operations. Xiong et al. (2015) proposed a new method in optimizing the parameters, such as drilling force, temperature, 5 high-speed photography and vibration signals in PCB micro hole drilling.

Hasan et al. (2017) had reviewed the modern improvements in micro drilling techniques. The study presented the advanced micro drilling methods and techniques, recent developments, process categorization and further requirements in this area. Choudhury et al. (2017) had fabricated a multi-functional machine, capable of performing both PCB milling and wood engraving. The input was given through the software system, which was then converted into corresponding G-codes. 
From the literature study, it is obvious that most of the researchers have concentrated on PCB drilling machine and, to the knowledge of authors, only a single digit publication has reported on PCB milling process. Moreover, high investment is needed to procure and maintain the currently available models. Hence, it was decided to develop a low-cost PCB milling machine, which can fulfil the requirements of SMEs of Indian industries and remain affordable.

\section{DESIGN AND MODELLING}

Milling process is carried on a commercially available circuit board of $1.15 \mathrm{~mm}$ thick with $120 \mu \mathrm{m}$ copper layer thickness. The copper layer is grown on a plastic substrate as it acts as an insulator. The circuit board is produced by compressing the layers of filler material accompanied with resin under high temperature and pressure with copper foils. The outer physical structure of the PCB milling machine is made using acrylic sheet, which is of lighter weight, rigid thermoplastic material with better mechanical strength than the standard window glass.

CNC Shield V3.0 is used as an interfacing board for controlling X, Y, Z-axis stepper motors. There are four port sets in the shield for stepper motor drivers to drive and control four stepper motors. Each stepper motor needs two IO port and six IO ports is used to drive three stepper motors. Arduino UNO an open-source prototyping platform in the field of electronics was employed to utilize hardware and software in a creative and effective way. Limit switch functionality have been added up by providing extra set of pins so that every axis has a "Top/+" and "Bottom/-". This additional functionality makes it easier to interface two limit switches for each axis. For an emergency stop button, these pins can be interfaced to an emergency stop pin provided within it.

Pins to control spindle motor speed and coolant flow have also been introduced in the shield.

GRBL command and control pins have help the user to include controls for pause/hold/reset, resume/start and abort/stop. The machine specifications are listed in the Table 1. 
Table 1: Machine Specification

\begin{tabular}{|c|c|}
\hline Drive System & Unipolar \\
\hline Step Angle & 1.8-degree full step, 0.9degree half-step \\
\hline Phase/Windings & $4 / 2$ \\
\hline Voltage \& Current & $12 \mathrm{~V}$ at $400 \mathrm{~mA}$ \\
\hline Holding Torque & $2000 \mathrm{~g}-\mathrm{cm}$ \\
\hline Weight & $0.24 \mathrm{~kg}(0.5 \mathrm{lbs})$. \\
\hline Max Continuous Power & $5 \mathrm{~W}$ \\
\hline Bearing Type & Ball \\
\hline Shaft Diameter & $0.197 \mathrm{in} .(5 \mathrm{~mm})$ \\
\hline Motor Footprint & 1.7 in. $\times 1.7 \mathrm{in}$. \\
\hline Motor Height & 1.5 in. \\
\hline Ambient Temperature & -10 deg C to $+55 \mathrm{deg}$ C \\
\hline Mounting Hole Space & 1.73 in. \\
\hline
\end{tabular}

Milling tool is used to engrave the circuit in the copper plate. This tool is available in various angle of the cutting edge. Increasing in angle will increase the accuracy of the circuit print and gives us a better-finished surface. Leadscrew (translational screw) is used as link mechanism in a CNC machine, to convert rotary motion into linear motion. It is commonly used in positioner mechanisms. Screw threads have higher frictional energy loses when compared to other link mechanisms.

V threads are not suitable for leadscrew because they possess high friction between the threads. Therefore, square threads with less friction and carry high power. Generally, bearings are designed to operate without lubrication. Linear motion bearing is used to provide free motion, which makes the motion smooth, offer low friction and high rigidity. The physical structure is made up of acrylic sheet. The size of the sheet used is of $10 \mathrm{~mm}$.

Acrylic is a shaft white rubbery material, transparent thermo-plastic, often used in sheet form 
as a lightweight and have higher resistance to shattering than glass. It is easy to handle, process and economic. In addition, it does not contain the harmful Bisphenol-A subunits found in polycarbonates. The overall modelling of the PCB milling machine is shown in the Fig 1 .

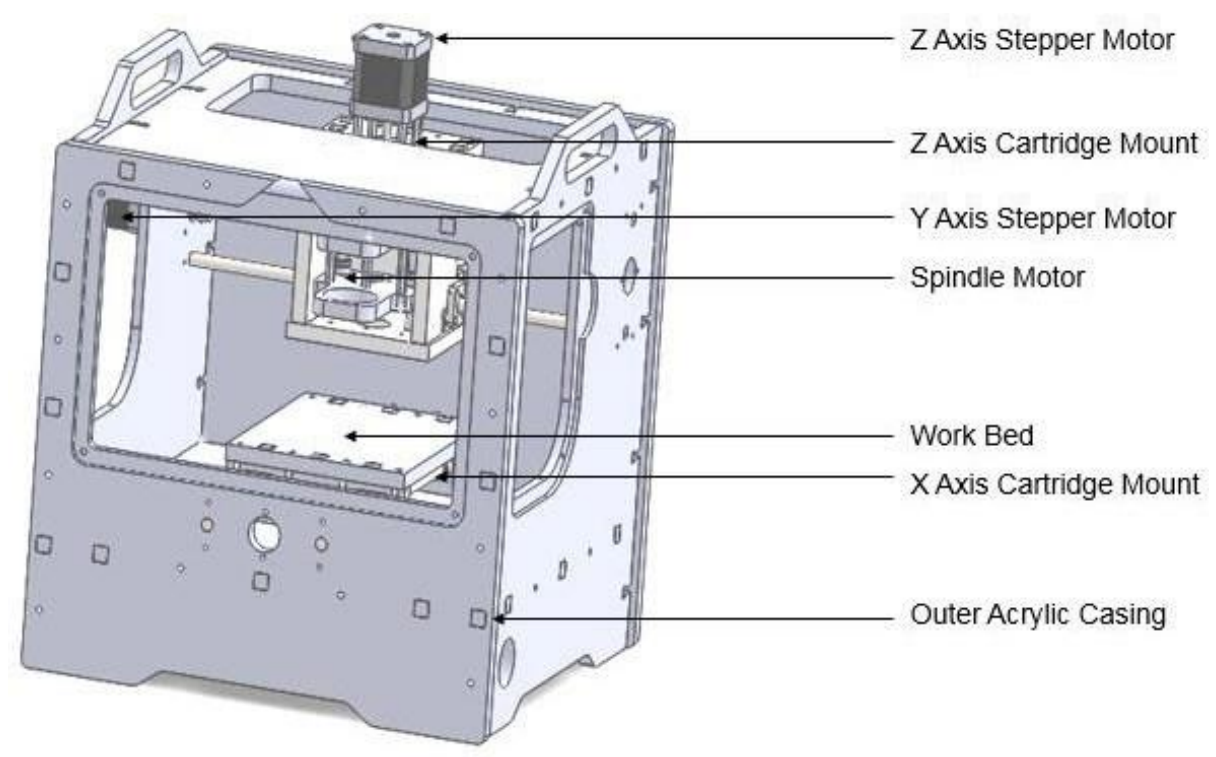

Figure 1: Modelling of PCB Milling Machine

Coupler, used to connect two cylindrical objects such as shafts, leadscrews etc., together at their ends for transmitting power. It is used to reduce the transmission of sudden loads from one object to another. It also alters the vibrational characteristics of rotor units. Flexible couplings can be used to reduce the varying degrees of misalignments up to 3 degrees and some parallel shaft misalignments.

Each product poses its own uniqueness that makes it stand out of the mark, as ELEVEN LABS is suitable for processing normal PCB it has a standard camera monitoring system that facilitates magnification and adjust the position.

Tools can be changed easily just by fastening the thread, LPKF places SMD components on PCB requires high accuracy therefore a semi-automatic, assembly system LPKF ProtoPlace S is used for PCB prototyping. 
Table 2: Comparison of Fabricated Model with Commercially Available Machine

\begin{tabular}{|c|c|c|c|c|c|}
\hline Description & Unit & $\begin{array}{c}\text { Developed } \\
\text { Model }\end{array}$ & Eleven labs & LPKF & cirQod \\
\hline $\begin{array}{c}\text { Working Area } \\
\text { (X-Y-Z-axes) }\end{array}$ & $\mathrm{mm}$ & $100 \times 150 \times 50$ & $229 \times 320 \times 60$ & $229 \times 305 \times 10$ & $100 \times 160$ \\
\hline $\begin{array}{c}\text { Table Size } \\
\text { (L x B) }\end{array}$ & $\mathrm{mm}$ & $130 \times 125$ & $296 \times 396$ & $229 \times 305 \times 10$ & $100 x 160$ \\
\hline $\begin{array}{c}\text { Machine Size } \\
\text { (WxDxH) }\end{array}$ & $\mathrm{mm}$ & $285 \times 315 \times 314$ & $435 \times 575 \times 430$ & $370 \times 300 \times 450$ & $280 x 470 x 380$ \\
\hline $\begin{array}{c}\text { Minimum Width } \\
\text { Line and Space }\end{array}$ & $\mathrm{mm}$ & 0.16 & 0.1 & 0.02 & - \\
\hline $\begin{array}{c}\text { Control Axis } \\
\text { Control Motor }\end{array}$ & - & $\mathrm{x}, \mathrm{y}, \mathrm{z}$ & $\mathrm{x}, \mathrm{y}, \mathrm{z}$ & $\mathrm{x}, \mathrm{y}, \mathrm{z}$ & $\mathrm{x}, \mathrm{y}, \mathrm{z}$ \\
\hline Max Travel Speed & $\mathrm{mm} / \mathrm{s}$ & 10 & 55 & Stepper & Stepper \\
\hline Max Spindle Speed & $\mathrm{rpm}$ & 1000 & 41000 & 30000 & 30000 \\
\hline $\begin{array}{c}\text { Spindle Motor } \\
\text { Type }\end{array}$ & - & DC & DC Spindle & Spindle & Spindle \\
\hline Drill-bit Size & $\mathrm{mm}$ & $0.2-1.2$ & $0.2-3.175$ & Optional & Optional \\
\hline Tool Change & - & Manual & Manual & Manual & Automatic \\
\hline Vision System & - & Optional & Present & Optional & Optional \\
\hline Input Supply & $\mathrm{V}$ & 12 & 24 & $90-240$ & 19 \\
\hline Machine Weight & $\mathrm{kg}$ & 17.5 & 28 & 18 & 14 \\
\hline
\end{tabular}

The cirQod poses a similarity with this developed machine as it is operated through G-CODE command. Almost every process performed by the above-mentioned machines can be done using this fabricated model at low cost. The necessary positions for operations are coded, making it easier to operate. A correlative study (machine description) of the fabricated model with the other commercially available machines are shown in the Table 2 . The A4988 chipset motor driver with built-in mode switches for micro-stepping operations is used to drive and control bipolar stepper motors (like NEMA 17) from1/4th step to 1/32nd step under the operating voltage of 12-35V (DC). The fabricated prototype model is shown in the Fig 2. 


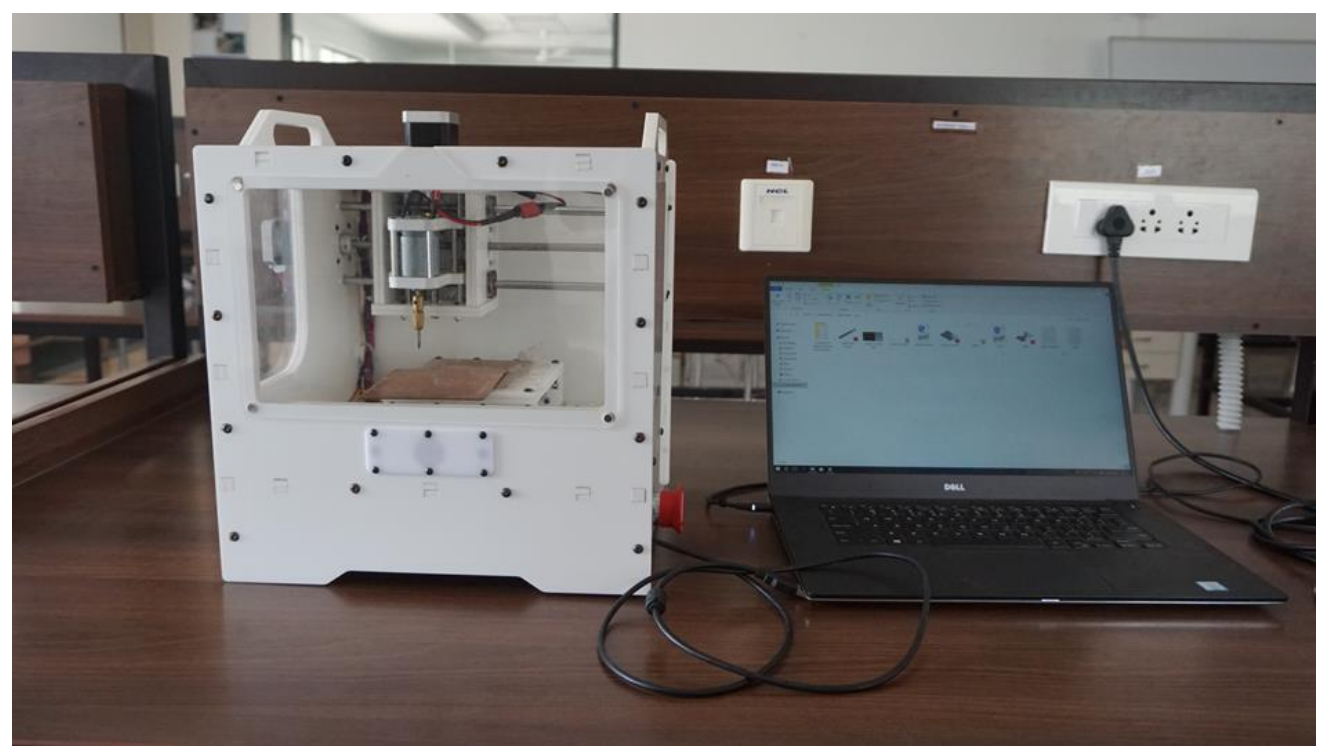

Figure 2: Fabricated Prototype of PCB Milling Machine

The A4988 chipset motor driver with built-in mode switches for micro-stepping operations is used to drive and control bipolar stepper motors (like NEMA 17) from1/4th step to 1/32nd step under the operating voltage of 12-35V (DC). By giving a single specific input pulse on the step count pin as input it drives the stepper motor resulting a one micro-step rotation. The A4988 motor driver is employed in areas of application where there is a need for high precision and good micro stepping. During micro-stepping or normal full or half stepping of the stepper motor, the control set in the A4988 stepper driver selects the decay-mode as "slow or mixed" automatically. If the current mode is in the mixed mode, the driver is set to a rapid decay initially, and then the mode changes to the slow decay mode for the intimation of the off time. Mixed mode provides in low audible stepper motor noise level, increase in step angle accuracy and low power loss.

\section{FABRICATION AND TESTING}

An electrical CAD software is used for designing the circuit diagram. At first, the circuit is built in a schematic format and the wiring connections are given to the blocks. The components were placed in the workspace. 
Wiring can be done manually or automatically using auto wiring feature in the software. The diameter of the wire and the diameter of pad can also be changed as per the required size of the circuit. After completing the circuit in schematic format, it is then converted to a board format using the board feature. In board format, the blocks are arranged in the right place and the final parameters are changed. The blocks are placed in the final board and then the board is adjusted as per the available workspace of the machine. The overall process flow is shown in the Fig 3.

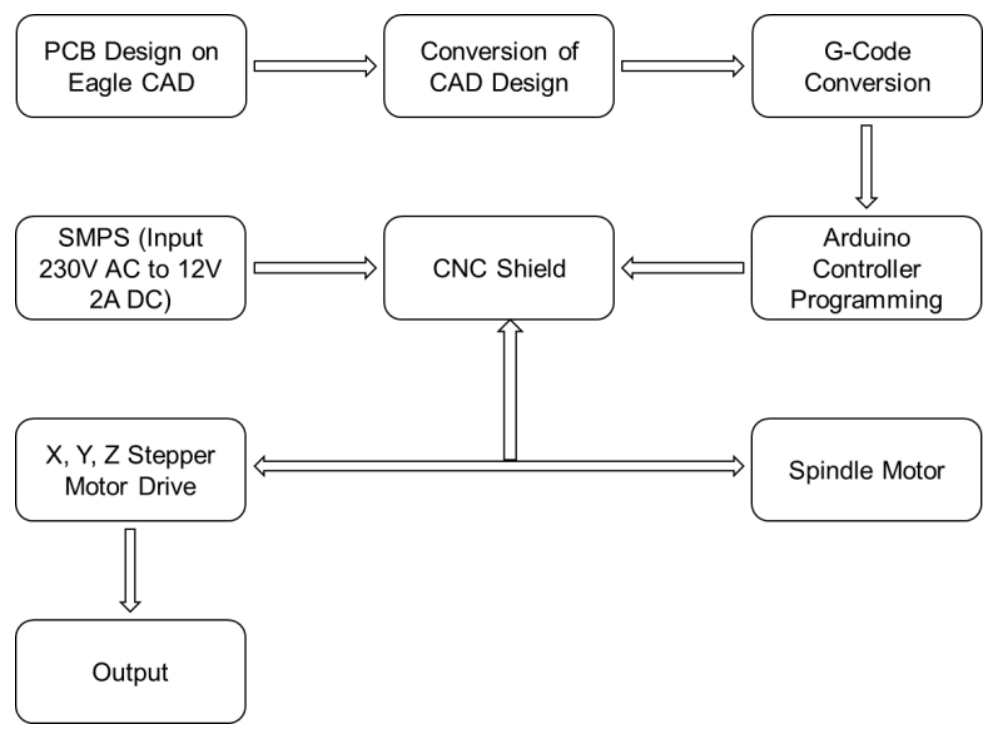

Figure 3: Machine Process Flow

Even though the assembly and wiring in the board format can be done automatically using auto router, the layers, which need be worked, can be changed in the layer properties. This will provide top and bottom layers where the wirings are formed.

After completing the routing, the outer layer of the board has to be formed, so the board, which is already present in the software, is reduced according to the size of the designed circuit. This code conversion will be done with the help of Java script. This is an additional downloaded file and to be installed separately. The completed board format will be converted to G-code, which is the understanding language for the CNC controller. ESTLCAM is the CNC controller software used to set the operating parameters of a PCB miller. The controller will be interfaced with the software and the G-code will be uploaded to the software.

The movement of the spindle can be analyzed in a sketch form using a display provided in the 
software. The flowchart for the program algorithm is shown in Fig 4.

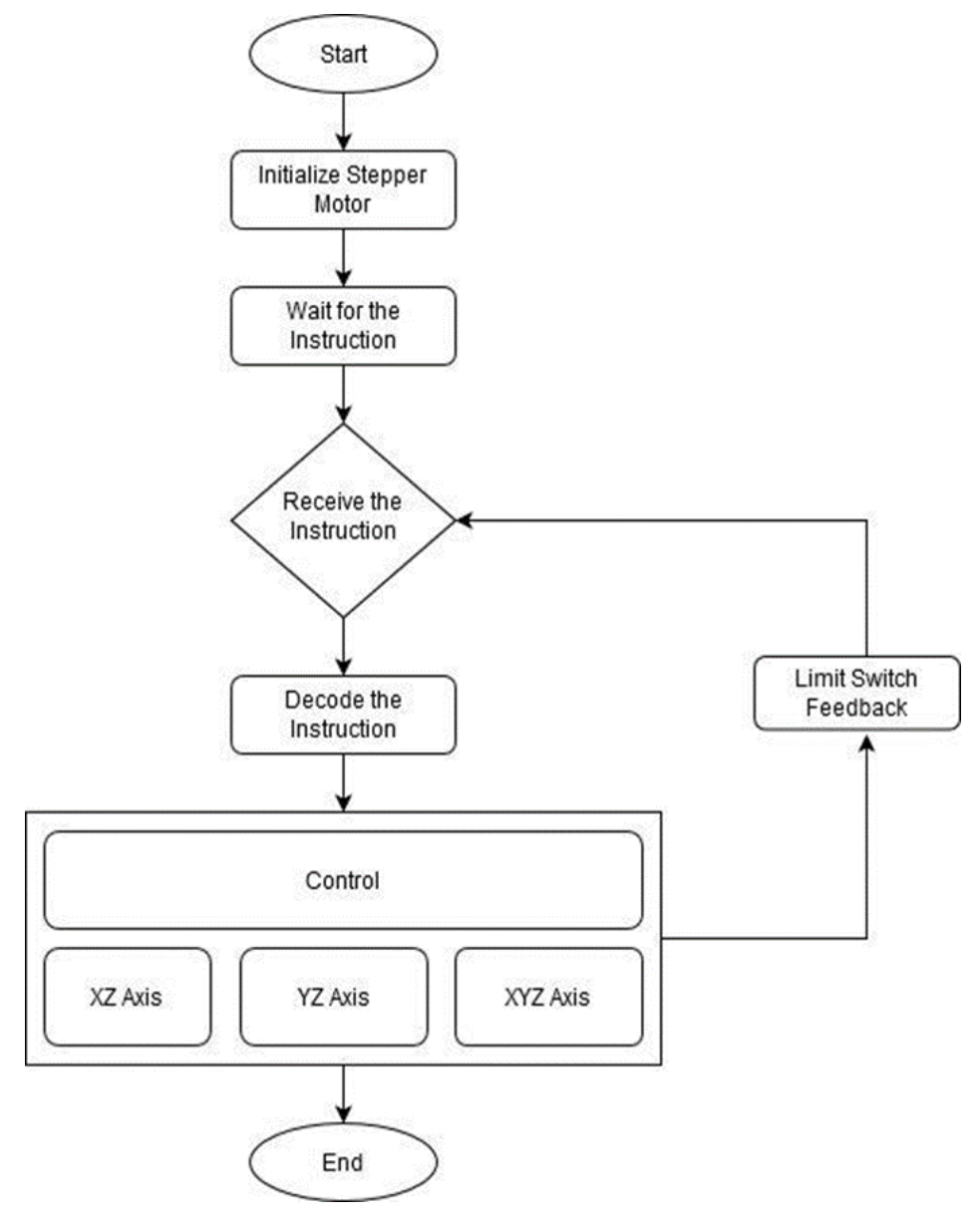

Figure 4: Program Flow (Control Axis Algorithm)

The stepping calculations is one of the main testing factors that to be performed in order to optimize the machine performance. The full and half stepping calculations are performed by comparing the input fed through software for motors and the final output movement. The calculations (Table 3) are performed for different angles from $360^{\circ}$ to $1 \mathrm{~cm}$ and the corresponding output results are recorded and the scaling factor is determined for both full stepping and half stepping. Based on the scaling factor value, the Arduino programming is reframed and the corresponding axis values are optimized. The output movement of the motor is calculated with a help of the digital encoder. 
Table 3: Full and Half Stepping Calculations

\begin{tabular}{|c|c|c|c|c|c|c|}
\hline \multirow{2}{*}{ Movement } & \multicolumn{3}{|c|}{ Full Stepping } & \multicolumn{3}{c|}{ Half Stepping } \\
\cline { 2 - 7 } & $\begin{array}{c}\text { Software } \\
\text { Input (mm) }\end{array}$ & $\begin{array}{c}\text { Result } \\
(\mathbf{m m})\end{array}$ & $\begin{array}{c}\text { Scaling } \\
\text { Factor } \\
(\mathbf{m m})\end{array}$ & $\begin{array}{c}\text { Software } \\
\text { Input (mm) }\end{array}$ & $\begin{array}{c}\text { Result } \\
(\mathbf{m m})\end{array}$ & $\begin{array}{c}\text { Scaling } \\
\text { Factor(mm) }\end{array}$ \\
\hline $360^{\circ}$ & 12 & 8 & 4 & 12 & 9 & 3 \\
\hline $720^{\circ}$ & 25 & 16 & 9 & 15 & 18 & 7 \\
\hline $1 \mathrm{~mm}$ & 1 & 0.6 & 0.4 & 1 & 0.8 & 0.2 \\
\hline $5 \mathrm{~mm}$ & 5 & 3 & 2 & 5 & 4 & 1 \\
\hline $1 \mathrm{~cm}$ & 10 & 6 & 4 & 10 & 8 & 2 \\
\hline
\end{tabular}

\section{RESULT AND DISCUSSION}

Step length calculation has to be performed based on the step angle (Equation 1). The number of steps per single revolution of the motor is calculated as shown in the Table 4 .

Table 4: Steps per Revolution Calculation

\begin{tabular}{|c|c|}
\hline Step Angle & Steps per Revolution \\
\hline 0.9 degrees & 400 \\
\hline 1.8 degrees & 200 \\
\hline 3.6 degrees & 100 \\
\hline 7.2 degrees & 50 \\
\hline 15 degrees & 24 \\
\hline
\end{tabular}

Step Length $=\frac{90}{N r}$

Step Angle $=360$ Degree $\frac{(N s-N r)}{(N s * N r)}$

$\frac{\text { Step }}{\text { Inch }}=\operatorname{Leadscrew}\left(\frac{\text { Revolution }}{\text { Inch }}\right) * \frac{1}{\text { Microstep }} * \operatorname{Motor}\left(\frac{\text { Step }}{\text { Revolution }}\right)$

$$
\frac{\left(\frac{360 \text { Degree }}{1 \text { Revolution }}\right)}{1.8\left(\frac{\text { Degree }}{\text { Step }}\right)}=\frac{\text { Step }}{\text { Revolution }}
$$


The number of stator poles $(\mathrm{Ns})$ and rotor poles $(\mathrm{Nr})$ are referred from the data sheet of the stepper motor. The step angle is calculated using the Equation 2. The stepper motor function has to be optimized using the motor steps per revolution, lead screw pitch and the clock speed of the motor. Micro stepping is an additional feature available in the controller to rotate the motor in a fraction of a step and it is calculated using Equation 3 and the steps per revolution is calculated using Equation 4. The physical design structure of a machine system mostly depends on specific physical limits, working space, component arrangement of various parts on the physical structure of the machine, control positions, space for additional features in case of future enhancements in the machine, physical dimensions of the machine such as height etc. Therefore, it is unavoidable to calculate the parameters in order to achieve a perfect design.

\section{CONCLUSIONS AND FUTURE WORK}

Based on the findings in the previous section, the material, which is the best alternative in terms of customer needs and business needs, should be produced domestically and should have competitive advantages in many ways such as quality and price. Hence, it should be feasible to produce an ideal PCB milling machine by slightly modifying the existing products. Increasing the process accuracy, in miniature components as well as in micro scale level are increasingly in demand in the sector of optics, automotive engineering, biotechnology, aerospace, and information technology industries and also in various engineering aspects. A cogitative approach in micro machining technology is to develop machines that are capable of giving output at a higher precision. Before designing the entire design and process must be properly analyzed considering the applications for which that particular machine is on high demand and suitable. The commonly cautioned issues or difficulties while designing and fabricating are motion and result accuracy, dynamic and physical stiffness, thermal and 
electrical stability.

\section{REFERENCES}

Alim, M., Goundar, S., Shamim, A., Pillai, M., Singh, R., Mamun, K. A., \& Mehta, U. (2015,). Automatic PCB drilling machine. In 2015 2nd Asia-Pacific World Congress on Computer Science and Engineering (APWC on CSE) (pp. 1-6).

Basniak, R., \& Catapan, M. F. (2012). Design of a PCB milling machine. In ABCM Symposium Series in Mechatronics (Vol. 5, pp. 1339-1348).

Choudhary, R., Titus, S. D., Akshaya, P., Mathew, J. A., \& Balaji, N. (2017). CNC PCB milling and wood engraving machine. In 2017 International Conference on Smart Technologies for Smart Nation (Smart Tech Con) (pp. 1301-1306).

H. Ferdinando, I. N. Sandjaja, G. Sanjaya, (2005) "Automatic Drilling Machine for Printed Circuit Board" Proceedings of the $6^{\text {th }}$ Symposium on Advanced Intelligent Systems, Surabaya Indonesia, pp. 218-222.

Hasan, M., Zhao, J., \& Jiang, Z. (2017). A review of modern advancements in micro drilling techniques. Journal of Manufacturing Processes, 29, 343-375.

Hodges, S. E., \& Richards, R. J. (1995). Uncalibrated stereo vision for PCB drilling. IEE Colloquium (Digest), (113), 0-5.

Suganthi, X. H., Natarajan, U., \& Ramasubbu, N. (2015). A review of accuracy enhancement in microdrilling operations. The International Journal of Advanced Manufacturing Technology, 81(1-4), 199-217.

Liang, X., Li, B., Fu, L., Wu, X., Shi, H., Peng, T., \& Xu, B. (2015). Mechanical drilling of PCB micro hole and its application in micro ultrasonic powder molding. Circuit World, 41(2), 87-94. 
Manda, V. R., Kampurath, V., and Msrk, C. (2018). 3D Printing and its Effect on Outsourcing: A Study of the Indian Aircraft Industry. Journal of Aerospace Technology and Management, 10, 1-22.

Ou, J., Maldonado, A., Saephan, C., Farahmand, F., \& Caggiano, M. (2014). A low-cost PCB fabrication process. In 2014 IEEE 64th Electronic Components and Technology Conference (ECTC) (pp. 2159-2162).

Alwis, P. L. S. C., Premarathna, A. S., Fonseka, Y. P., Samarasinghe, S. M., \& Wijayakulasooriya, J. V. (2014). Automated printed circuit board (PCB) drilling machine with efficient path planning. In SAITM research symposium on engineering advancements (pp. 159-162).

Shan, Y., Xu, C., \& Jiang, Q. (1998). Based-on computer vision auto-aligning drilling machine for PCB [3558-14]. In PROCEEDINGS-SPIE THE INTERNATIONAL SOCIETY FOR OPTICAL ENGINEERING (pp. 74-80).

Tahir, Z., Abu, N. A., Sahib, S., \& Herman, N. S. (2010). CNC PCB drilling machine using novel natural approach to Euclidean TSP. In 2010 3rd International Conference on Computer Science and Information Technology (Vol. 5, pp. 481-485).

Zheng, L. J., Wang, C. Y., Song, Y. X., Yang, L. P., Qu, Y. P., Ma, P., \& Fu, L. Y. (2011). A review on drilling printed circuit boards. In Advanced Materials Research (Vol. 188, pp. 441-449).

Balasubramanyam, N. \& G. Prasanthi, G. (2014). Design and fabrication of an Automatic Pc-Based Drilling Machine, Hctlopen International Journal of Technology Innovations and research (Vol. 7). 